Public health

\section{Choosing or losing health?}

\section{David J Hunter}

\section{The public health community's voice needs to be heard as an advocate for sustained political will and for the stewardship role of governments.}

he neo-liberal thinking is gripping health care reform in many countries with its focus on market style competition and individual choice, a similar revolution may be underway in public health policy. The example of recent developments in England is instructive and offers a warning to other countries that are also rediscovering public health or are perhaps discovering it for the first time. Although welcome and overdue, the manner in which the (re)discovery is taking place and its implications for public health policy and practice may be less encouraging.

The government published its English public health policy statement in November 2004 to general acclaim from the public health community. ${ }^{1}$ Indeed, the reception given to the policy proposals was perhaps a little too uncritical. This was certainly the view of the United Kingdom Public Health Association (UKPHA), which published a critical assessment of the policy statement and the political ideology underpinning it. ${ }^{2}$ It concluded that the policy is seriously flawed, pulls too many punches (for example, refusing to opt for a total smoking ban in public places), and is emasculated by its entanglement with the choice agenda that has little or no place in public health. In fact, far from being a progressive document that builds on the previous health policy statement, Saving Lives: Our Healthier Nation, published in 1999, ${ }^{3}$ the new statement, Choosing Health, displays a number of regressive features.

To understand the shift from a public to a private conception of public health policy, for that is in essence what Choosing Health amounts to, it is necessary to trace its antecedents. These lie in the two seminal reports produced by Derek Wanless, the Treasury's special adviser. ${ }^{45} \mathrm{~A}$ former banker, he was invited to assess the pressures and challenges facing the British NHS over a 20 year period until 2022 and to give an opinion on whether a publicly funded health care system was sustainable for the duration. He concluded it would be but only if a number of things happened, among them getting a grip on demand by being less preoccupied with downstream acute care and more willing to invest in, and prioritise, upstream preventive interventions. He produced three scenarios and the most ambitious of these, the fully engaged scenario, was the one the government opted for. It did so largely because if successful it would save the NHS a significant amount of funding because the population would be both healthier and taking more responsibility for its health.

Wanless developed his views on public health in his second report where he emphasised the need for the NHS to be rebalanced from a sickness to a health service. He claimed that the problem lay not in policy prescriptions but in the lack of their effective implementation over some 30 years. Political will seemed to be lacking despite good intentions and favourable rhetoric. Reflecting this weak determination to act he pointed to a public health workforce that was not fit for purpose. It lacked many of the essential skills to change individual behaviour (for example, social marketing) and was spread too thinly across multiple organisations thereby lacking capacity to make a sustained impact. In addition, the evidence base remained weak so that too little systematic evidence existed to inform policy about what worked and which interventions were cost effective.

Wanless's prescription lay principally in getting "a realignment of incentives in the system to focus on reducing the burden of disease and tackling the key lifestyle and environmental risks". The government's response to Wanless's second report was muted. There was evidence of some discomfort between the Treasury and Department of Health on who was in the driving seat in respect of public health issues, with the health department believing that leading on health was part of its remit and should not be usurped by the Treasury. It therefore crafted a case for giving public health a high priority on the grounds that during its first seven years or so in office the government had been obliged to sort out the NHS in respect, inter alia, of waiting lists, and poor quality in hospital and primary care services. With these issues having been brought under control, it was appropriate to turn attention to wider health issues.

However, it was debatable whether the government needed another public health policy on top of the one published in 1999 after a lengthy period of public consultation on a draft version produced in 1998. There did not seem to be a self evident need, or appetite, for another policy review especially one that would take some six months to conclude after a major public consultation exercise. So what possible explanation can be given? Two reasons can be advanced.

Firstly, announcing a policy review followed by a policy statement enabled the government simultaneously to show it was taking action on public health while at the same time defusing Wanless's critique of slow progress-in effect kicking it into the long grass.

Secondly, between the publication of the 1999 policy statement, Our Healthier Nation, and the arrival of the second Wanless report in early 2004, the government had set in train a "quiet revolution" in the NHS that entailed introducing market style incentives and competitive behaviour that went far beyond anything contemplated by the internal market reforms of the early 1990s. The rhetoric from 2002 was about devolution, putting power back to the frontline, reducing central control, and giving patients and public more choice. The 1999 public health statement arguably needed updating and bringing into line with the current New Labour mantra of choice and individualism combined with market style incentives to modify lifestyles.

A comparison between the 1999 policy document and the 2004 updated version illustrates the different emphasis and language evident. Both documents cite the importance of individual choice and acknowledge that government has a part to play in creating the conditions in which people could lead healthier lives. But their significance is reversed. Compare what the then health ministers said in their foreword to the 1999 public health statement-"Now we want to see far more attention and Government action concentrated on the things which damage people's health which are beyond the control of the individual" - with what the prime minister said in his foreword to the 2004 policy statement: "We are clear that Government cannot...pretend it can 'make' the population healthy. But it can-and should-support people in 
making better choices for their health..."

The difference between the two documents suggests a reduced role for government and a renewed focus on individual lifestyle-notions enshrined by the first two underlying principles of Choosing Health-informed choice, and personalisation. While there are positive features arising from such an approach, including the focus on health promotion as well as proposed changes to the use of the workforce harnessing the skills of pharmacists, dentists, and others, the weaknesses are more striking, representing as they do a retreat by government from its earlier optimism and commitment to healthy public policy. ${ }^{6}$ In contrast with its predecessor, Choosing Health is notable for the absence of sound leadership from central government. The Minister for Public Health-a new ministerial post introduced by the government in 1997-does not even get a mention. Health inequalities receive only passing reference and the underlying health determinants are virtually ignored. Local government remains overshadowed by what is perceived to be principally once again an NHS led agenda. $^{7}$ But it is the fixation on individual choice-a notion that now runs through all public policy-which is the most significant difference. Health is seen as firmly the responsibility of the individual-in contrast with the first public health minister's criticism of the Conservative government for its excessive emphasis on lifestyle issues.

It has to be asked whether the challenges facing the government from widening health inequalities can effectively be tackled by such a prominent focus on the individual. The government's favourite think tank, the Institute for Public Policy Research, in an audit of injustice in the UK concluded that "Britain is far from being a just society. Levels of child poverty continue to surpass those of many of our more successful European partners and inequalities in income, wealth and well-being remain stubbornly high". Other commentators have concluded that "since Victorian times, such inequalities have never been as high".

In its response to the 2004 policy statement on public health, the UKPHA suggested that alternative principles could have been adopted along the lines of the following: combating health inequalities, promoting sustainable development, and challenging antihealth forces. Instead, the document concentrates almost entirely on the individual and ignores or downplays the significance of community oriented preventive action for health.
Where does all this leave public health? Public health practitioners cannot simply ignore such trends or what seems to be a reconceptualisation of their task. Indeed, the words of Julio Frenk, Mexico's Minister for Health, written almost 25 years ago, seem as apposite now as then ${ }^{10}$ :

Public health has historically been one of the vital forces leading to...collective action for health and well-being.... The widespread impression exists today that this leading role has been weakening and that public health is experiencing a severe identity crisis as well as a crisis of organization and accomplishment.

As governments either enthusiastically seize, or become reluctant converts to, the so called Anglo-Saxon model of the business of governance in a global context, a number of trends are becoming all too evident. There is a shift underway from the post-war welfare state model to the market state. ${ }^{11}$ Alongside this development are shifts from central leadership to local autonomy, and from paternalism to consumerism. These are resulting in a changing role for, and scope of, the public realm. ${ }^{12}$ The difficulty is that no one is yet able to articulate convincingly what the public realm will look like in future. This vacuum presents public health with a serious dilemma as by definition its work is carried out in the public realm and lies outside a market framework.

The marketisation of public policy cannot simply be ignored as a passing whim. It goes to the heart of the neoliberal consensus emerging across many countries in the West, including much of the so called "New Europe" comprising central and eastern European states. Its defining characteristics are precisely those that are to the fore in the English public health policy statement although the government does not use such terms to describe its approach. There is instead the language of choice; a greater reliance on the individual that requires a transfer of risk; a thinner, more transactional and contingent relationship between the State and citizen; a preference for consumerism over collectivism, and for public-private partnerships in the delivery of policies and services. In short, health is to be defined and marketed in terms of personal fitness, body imagery, and individual achievement.

The English public health policy statement closes with the ringing words: "This is the beginning of a journey to build health into Government policy and ensure that health is everybody's business". In fact, it seems that health is some people's business more than others as the government's stance shows a retreat from enlightened government action that resulted in, for example, seat belt legislation and has enabled many countries to legislate for smoke free public places. Simply offering people information and education to change lifestyles will not result in healthier eating habits or the uptake of physical exercise regimens. ${ }^{13}$

The paradox for public policy is that at precisely the time public health has risen up the policy agenda, it has become subjected to the neo-liberal Anglo-Saxon embrace that is narrowing the focus and locus of public health and placing responsibility for health increasingly at the personal level. Yet, at the same time, the determinants of health and the most powerful means for health improvement are increasingly located at regional, national, and global levels. ${ }^{14}$

The public health community's voice needs to be heard as an advocate for sustained political will and for government's stewardship role to be championed both within nation states and increasingly between them. ${ }^{15}$ Reducing public health to health education and promotion is misguided and regressive, as is a heavy reliance on health care systems to lead the paradigm shift where the pull of the acute sector remains powerful and likely always to drive out an upstream approach. Instead, what is needed is much closer linkage between public health and sustainability so that health becomes a central integrating function of sustainable development strategies. But for this to happen, government action is unavoidable, combined with a clear commitment to a collective response. There are limits to markets and to viewing individuals as consumers exercising unfettered choice. It is time we acknowledged these and acted accordingly.

J Epidemiol Community Health 2005;59:10101012.

doi: 10.1136/jech.2005.035121

Correspondence to: Professor D J Hunter, School for Health, Wolfson Research Institute, Durham University Queen's Campus, Thornaby, Stockton on Tees TS17 6BH, UK; d.j. hunter@durham.ac.uk

\section{REFERENCES}

1 Secretary of State for Health. Choosing health: making healthier choices easier. $\mathrm{Cm} 6374$ London: The Stationery Office, 2004.

2 United Kingdom Public Health Association (UKPHA). Choosing health or losing health? A response from the UKPHA to the white paper choosing health. London: UKPHA, 2005.

3 Secretary of State for Health. Saving lives: our healthier nation. $\mathrm{Cm}$ 4386. London: HMSO, 1999 
4 Wanless D. Securing our future health: taking a long-term view. Final report. London: HM Treasury, 2002

5 Wanless D. Securing good health for the whole population. Final Report. London: HM Treasury/ Department of Health, 2004

6 Joffe M, Mindell J. A tentative step towards healthy public policy. J Epidemiol Community Health 2004:58:966-8.

7 Local Government Association, UKPHA, NHS Confederation. Releasing the potential for the public's health. London: NHS Confederation, 2004.
8 Paxton W, Dixon M. The state of the nation: an audit of injustice in the UK. London: Institute for Public Policy Research, 2004.

9 Shaw M, Davey Smith G, Dorling D. Health inequalities and New Labour: how the promises compare with real progress. $B M$ 2005;330:1016-21.

10 Frenk J. The new public health. In: Pan American Health Organisation. The crisis of public health: reflections for debate. Washington: PAHO/ WHO, 1992.

11 Bobbitt P. The shield of Achilles: war, peace and the course of history. London: Penguin, 2003.
12 Gamble A, Wright T, eds. Restating the state? Oxford: Blackwell/The Political Quarterly, 2004.

13 Reeves MJ, Rafferty AP. Healthy lifestyle characteristics among adults in the United States, 2000. Arch Intern Med 2005; 165:854-7.

14 Beaglehole R, Bonita R. Strengthening public health for the new era. In: Beaglehole R, ed. Global public health: a new era. Oxford: Oxford University Press, 2004

15 Kickbusch I. The end of public health as we know it: constructing global public health in the 21 st century. Public Health 2004;118:463-9. of polygons containing objects linked by (weighted) arrows and are designed primarily to show the aetiology of a topic that has been delineated into its constituent components. Figure 1, as reproduced from an article by Starfield, is an example of this type of conceptual diagram. ${ }^{4}$

Descriptive/structural diagrams are designed to clearly delineate layers of phenomena or types of objects to aid in organising and synthesising knowledge, designating variables, and so on. Figure 2, as reproduced from Barrett et $a l$, is an example of this second type of conceptual diagram. ${ }^{5}$ Causal/associative models generally provide predictions that can be tested and falsified whereas descriptive/structural diagrams provide paradigmatic ways of thinking through phenomenon.

The most common failing in the use of conceptual diagrams is their inclusion in an article devoid of sufficient description in the text. This is akin to presenting tabular or graphical data without any interpretation and, not surprisingly, severely limits the utility of these diagrams for potential users. As an examdiagrams including aspects of both types. Causal diagrams usually consist
The online Oxford English Dictionary defines a diagram as a "set of lines, marks, or tracings which represent symbolically the course or results of any action or process" or a "delineation used to symbolize related abstract propositions or mental processes". Adapted from what Earp and Ennett $^{1}$ call a "conceptual model", we define a conceptual diagram as a "diagram of proposed relationships among a set of concepts, factors, or variables about a particular hypothesis, question, context, problem or topic". Conceptual diagrams are used to organise and synthesise knowledge, define concepts, provide explanations for causal and associative linkages, generate hypotheses and specific research questions, plan and target interventions, designate variables to be operationalised, and anticipate analytical approaches. ${ }^{1}$ Conceptual diagrams delineate the scope of an inquiry and break up phenomenon into manageable pieces that map out the conceptual terrain in an area of interest. ${ }^{2}$ These diagrams also assist in: interpreting statistical models, identifying knowledge gaps, directing future research,

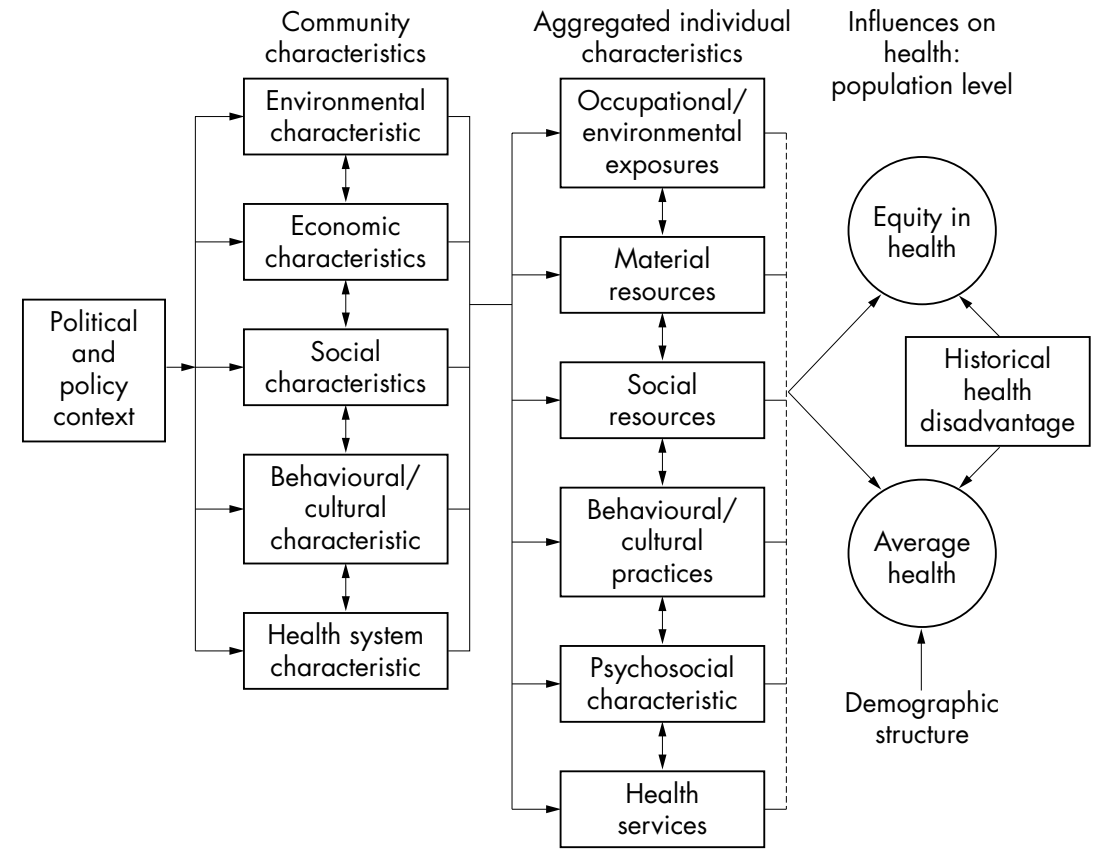

Figure 1 Example of a causal/associative conceptual diagram. ${ }^{4}$ 


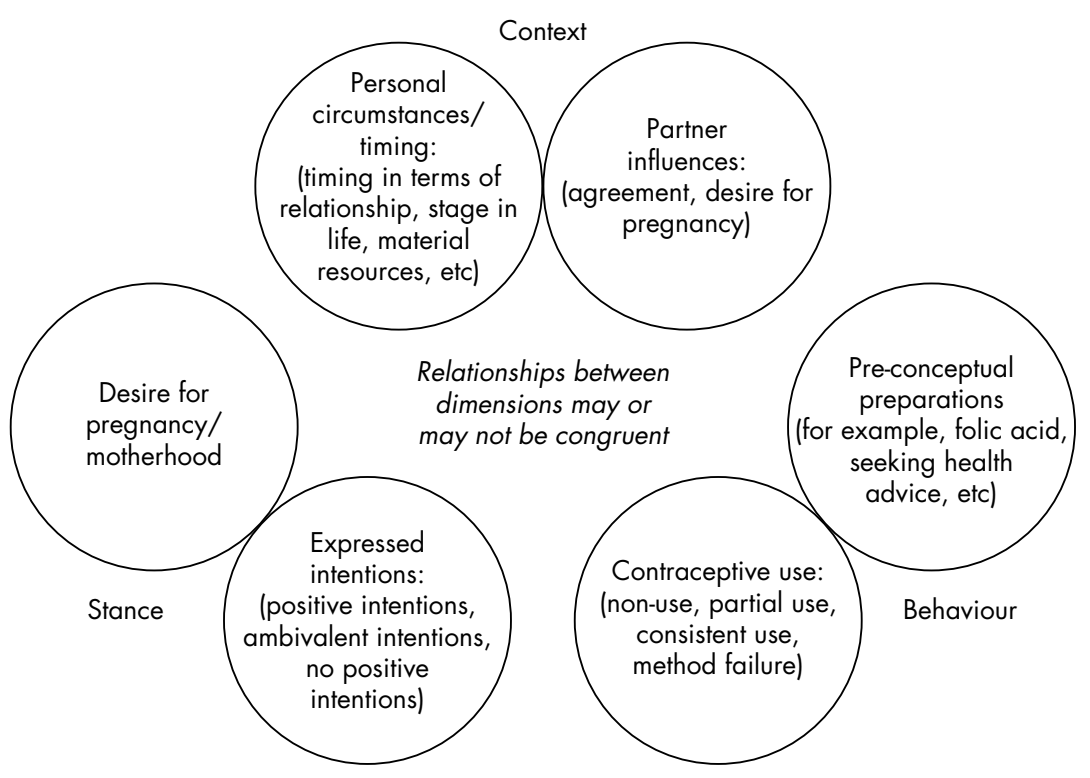

Figure 2 Example of a descriptive/structural conceptual diagram. ${ }^{5}$

ple, figure 4 in Moreau et al, which is a three dimensional conceptual diagram depicting the relation between job conditions and sick leave as mediated by a mix of positive and negative health related outcomes, is presented with no explanation whatsoever. ${ }^{6}$ In contrast, Starfield devotes over a quarter of her editorial to describing her conceptual diagram. ${ }^{4}$

Before creating a conceptual diagram it is important to decide on its scope: what is the topic of interest, how many levels/types of phenomenon will be included to convey the necessary relations and what portion of the causal web or typology will be described. The best conceptual diagrams are explicit about their scope, are informed and described by theories and/or empirical evidence and "parsimoniously convey complex information, allowing the viewer to quickly visualize and grasp complicated relationships". ${ }^{1}$ Diagrams that attempt to cover too great a scope as well as those that could just as easily

\section{What this paper adds}

This article seeks to focus attention on the role of conceptual diagrams in public health research by illustrating key points in relation to the use and misuse of diagrams be described in a single sentence should be avoided.

For instance, the figure included in Droomers et $\mathrm{al}^{7}$ which consists of three boxed concepts joined by two arrows (between boxes one and two and between boxes two and three) in a single causal line, is described sufficiently in the text as: "the association between parental socioeconomic status and adolescents' alcohol consumption might be explained by...predictors of high alcohol consumption". ${ }^{7}$ Nothing is gained by the inclusion of a conceptual diagram in this case.

Given the recognised complexity of developing meaningful conceptual diagrams, public health researchers have been slow to adopt multiple spatial and temporal scales, nested hierarchies of socioeconomic and biophysical environments and feedback loops between phenomenon, ${ }^{8}$ as used in disciplines such as ecology. However, as conceptual diagrams incorporate ecological approaches to situating individuals in social, cultural, and physical worlds, ${ }^{9}$ it is vital to retain a "clearly designated category for the individual" ${ }^{\prime 10}$ so as not to fall into the trap of over-emphasising structure at the expense of individual agency. ${ }^{11}$

It is important to recognise that "constructing a conceptual [diagram] is as much art as science". ${ }^{\prime}$ Although there are no hard and fast rules or easy checklists for their construction it is, none the less, clear that readers appreciate elegant, informative, visually edifying, and adequately described diagrams, making it all the more important that the construction and use of conceptual diagrams is taken seriously in public health research.

J Epidemiol Community Health 2005;59:10121013.

doi: 10.1136/jech.2005.036913

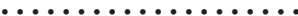

Authors' affiliations

Y Paradies, Menzies School of Health

Research, Charles Darwin University and

Centre for Health and Society, University of

Melbourne, Australia

M Stevens, Menzies School of Health

Research, Charles Darwin University

Correspondence to: Mr Y Paradies, Menzies

School of Health Research, PO Box 41096 ,

Casuarina, Northern Territory, Australia; yin. paradies@menzies.edu.au

Funding: none.

Competing interests: none.

\section{REFERENCES}

1 Earp JA, Ennett ST. Conceptual models for health education research and practice. Health Educ Res 1991;6:163-71

2 Australian Bureau of Statistics. Measures of Australia's progress. Canberra: AGPS, 2004.

3 Turrell G, Oldenburg B, McGuffog ID, et al. Socioeconomic determinants of health: towards a national research program and a policy and intervention agenda. Canberra: School of Public Health, Queensland University of Technology, 1999.

4 Starfield B. Equity in health. J Epidemiol Community Health 2002;56:483-4.

5 Barrett G, Smith SC, Wellings K. Conceptualisation, development, and evaluation of a measure of unplanned pregnancy. $J$ Epidemiol Community Health 2004;58:426-33.

6 Moreau M, Valente F, Mak R, et al. Occupational stress and incidence of sick leave in the Belgian workforce: the Belstress study. J Epidemiol Community Health 2004;58:507-16.

7 Droomers M, Schrijvers CTM, et al. Occupational level of the father and alcohol consumption during adolescence; patterns and predictors. J Epidemiol Community Health 2003;57:704-10.

8 VanLeeuwen JA, Waltner-Toews D, Abernathy T, et al. Evolving models of human health toward an ecosystem context. Ecosystem Health 1999:5:204-19.

9 Oldenburg B, Burton N, Parker E. Health promotion and environmental health. In: Cromar N, Cameron S, Fallowfield H, eds. Environmental health in Australia and New Zealand. South Melbourne: Oxford University Press, 2004:213-26.

10 Anderson I. Aboriginal health, policy and modelling in social epidemiology. In: Eckersley R, Dixon J, Douglas B, eds. The social origins of health and well-being. Cambridge: Cambridge University Press, 2001:247-58.

11 Kowal E, Paradies Y. Ambivalent helpers and unhealthy choices: public health practitioners' narratives of indigenous ill-health. Soc Sci Med 2005;60:1347-57. 